\title{
Kelayakan Geosite dan Geomorphosite Kawasan Desa Wisata Limbasari sebagai Potensi Geowisata Desa Limbasari
}

\author{
${ }^{1}$ Huzaely Latief Sunan*, ${ }^{2}$ Widhiatmoko Herry Purnomo, ${ }^{1}$ Akhmad Khahlil Gibran, \\ ${ }^{5}$ Suroso, ${ }^{3}$ Teguh Cahyono, ${ }^{3}$ Nur Chasanah, ${ }^{4}$ Tigar Putri Adhiana, ${ }^{4}$ Rani Aulia Imran, \\ ${ }^{5}$ Gito Sugiyanto, ${ }^{2}$ Hesti Susilawati, ${ }^{1}$ FX Anjar Tri Laksono
}

\begin{abstract}
${ }^{1}$ Program Studi Teknik Geologi, Fakultas Teknik, Universitas Jenderal Sudirman, Purwokerto, Indonesia ${ }^{2}$ Program Studi Teknik Elektro, Fakultas Teknik, Universitas Jenderal Sudirman, Purwokerto, Indonesia ${ }^{3}$ Program Studi Teknik Informatika, Fakultas Teknik, Universitas Jenderal Sudirman, Purwokerto, Indonesia ${ }^{4}$ Program Studi Teknik Industri, Fakultas Teknik, Universitas Jenderal Sudirman, Purwokerto, Indonesia ${ }^{5}$ Program Studi Teknik Sipil, Fakultas Teknik, Universitas Jenderal Sudirman, Purwokerto, Indonesia
\end{abstract}

\section{*Corresponding Author}

Jl. Mayjen Sungkono KM No.5, Blater, Purbalingga, Kabupaten Purbalingga, Jawa Tengah 53371 Email: huzaely.sunan@unsoed.ac.id

$\begin{array}{llll}\text { Received: } & \text { Revised: } & \text { Accepted: } & \text { Published: } \\ \text { 23 October 2020 } & \text { 4 December 2020 } & \text { 15 December 2020 } & \text { 25 December 2020 }\end{array}$

\begin{abstract}
Abstrak
Desa Limbasari secara geografis terletak di Kecamatan Bobotsari Kabupaten Purbalingga. Desa Limbasari merupakan salah satu desa wisata yang baru di Kabupaten Purbalingga. Desa ini mempunyai potensi yang besar untuk dikembangkan sebagai destinasi wisata dalam segi wisata kebumian dan geoheritage. Daya tarik wisata yang ada berupa River Tubing, landscape pegunungan batuan gunung api yang terdapat batu jasper hijau "nogo sui", dan situs kebudayaan prasejarah. Di samping itu keunikan budaya serta sejarah masyarakat juga menjadi daya tarik bagi masyarakat perkotaan. Tujuan dari pengabdian masyarakat adalah mengulas kelayakan geosite dan geomorphosite di Desa Limbasari sebagai sebuah solusi bagaimana memanfaatkan kekayaan geologi beserta berbagai dinamikanya untuk kegiatan wisata edukasi dan ekonomi yang berwawasan lingkungan. Metode yang digunakan adalah pemetaan potensi geologi sebagai kawasan wisata, inventarisasi pada lokasi yang mempunyai cagar budaya dan sejarah serta wawancara dengan pihak terkait dan studi literatur. Dari hasil kelayakan di kawasan wisata Limbasari mempunyai nilai kelayakan antara 47.5\% - 73.5\%. Dengan demikian, Kawasan Desa Wisata Limbasari, Kabupaten Purbalingga layak menjadi objek geowisata dengan aspek penilaian didasarkan pada nilai kuantifikasi berbagai keindahan antara alam dan proses geologi yang mengontrol terbentuknya obyek geowisata tersebut.
\end{abstract}

Kata kunci: Limbasari; Purbalingga; Geowisata; Geosite; Morphosite.

\begin{abstract}
Limbasari Village is geographically located in Bobotsari Subdistrict, Purbalingga Regency. Limbasari Village is one of the new tourism villages in Purbalingga Regency. This village has great potential to be developed as a tourist destination in terms of earth tourism and geoheritage. The tourist attractions are River Tubing, mountainous volcanic mountain landscape with green jasper stone "nogo sui", and
\end{abstract}


prehistoric cultural sites. In addition, the cultural and historical uniqueness of the community is also an attraction for urban communities. The purpose of this study is to review the potential of Geotourism and geoheritage in the Village of Limbasari as a solution to how to utilize the rich geological and cultural sites along with various dynamics for educational activities that are environmentally friendly education and economy. The method used in this study is the mapping of geological potential as a tourist area, an inventory of locations that have cultural and historical reserves as well as interviews with relevant parties and literature studies. From the results of research in the tourist area Limbasari has a feasibility value between 47.5\% - 73.5\%. Thus, the Limbasari Tourism Village Area, Purbalingga Regency deserves to be a geotourism object with the assessment aspect based on the quantification value of various beauties between nature and the geological process that controls the formation of the geotourism object.

Keywords: Limbasari; Purbalingga; Geotourism; Geosite; Morphosite.

\section{PENDAHULUAN}

Menurut Inskeep (2010), desa wisata adalah kawasan pedesaan yang memiliki beberapa karakteristik khusus untuk menjadi daerah tujuan wisata. Sedangkan menurut (Kirchner \& Kubalíková, 2014) kawasan desa wisata juga harus memiliki berbagai fasilitas untuk menunjang daerah tersebut sebagai kawasan tujuan wisata (Ernawati et al., 2019; Permadi et al., 2016; Wijaya \& Widodo, 2015). Berbagai fasilitas ini akan memudahkan para pengunjung desa wisata dalam melakukan kegiatan wisata (Prihasta \& Suswanta, 2020). Fasilitas yang dimiliki oleh kawasan desa wisata antara lain sarana akomodasi yaitu menyediakan sarana penginapan berupa pondok-pondok wisata (homestay) sehingga para pengunjung dapat menikmati suasana pedesaan yang masih khas (Sidik, 2015). Pengembangan daerah tertentu menjadi suatu kawasan geowisata tentunya akan memberikan dampak yang baik bagi kehidupan masyarakat dalam berbagai aspek kehidupan seperti ekonomi, sosial, budaya, dan infrastruktur (Pakpahan, 2018). Akan tetapi dalam menentukan suatu daerah sebagai kawasan geowisata perlu dilakukan analisis terlebih dahulu (Hidayat et al., 2017; Riswanto \& Andriani, 2018). Analisis yang umumnya dilakukan adalah analisis geosite dan geomorphosite. Geosite dan Geomorphosite merupakan bentang lahan yang memiliki potensi sebagai situs pariwisata dan memiliki nilai berdasarkan sudut pandang penilaian manusia (Laksono et al., 2020). Analisis ini ditujukan untuk memberikan penilaian terhadap parameter - parameter tertentu seperti nilai pendekatan ilmiah, nilai pendidikan, nilai ekonomi, nilai konservasi dan nilai tambah (keindahan, budaya, faktor geologi) pada daerah tertentu (Murdana, 2015).

\section{METODE}

Studi kelayakan ini menggunakan 3 tahapan. Tahap pertama yaitu studi pustaka mengenai kondisi geologi daerah pengabdian, serta melakukan wawancara dengan ketua POKDARWIS bagaimana konsep geowisata dan kelayakan geosite dan geomorphosite. Tahap kedua adalah pengambilan data lapangan berupa data primer dan data sekunder (Citra). Tahap ketiga adalah penghitungan kelayakan geosite dan geomorphosite berdasarkan metode kuantifikasi yang terdapat pada tabel I menurut (Nuhung, 2016). 


\section{Indonesian Journal of Community Services}

Volume 2, No. 2, November 2020

http://jurnal.unissula.ac.id/index.php/ijocs

DOI: http://dx.doi.org/10.30659/ijocs.2.2.109-117

\section{HASIL DAN PEMBAHASAN}

Berdasarkan hasil dari pengamatan lapangan, terdapat 3 geosite dan 1 geomorphosite (Gambar 1) yang berada di kawasan Geowisata Limbasari. Masing-masing geosite dideskripsikan tentang lokasi detail, nilai analisis kuantifikasi berdasarkan tabal analisis geosite dan geomorphosite (Zaenudin et al., 2019), tinjauan geologi, dan produk daya tarik wisata. Berikut adalah deskripsi masing-masing geosite:

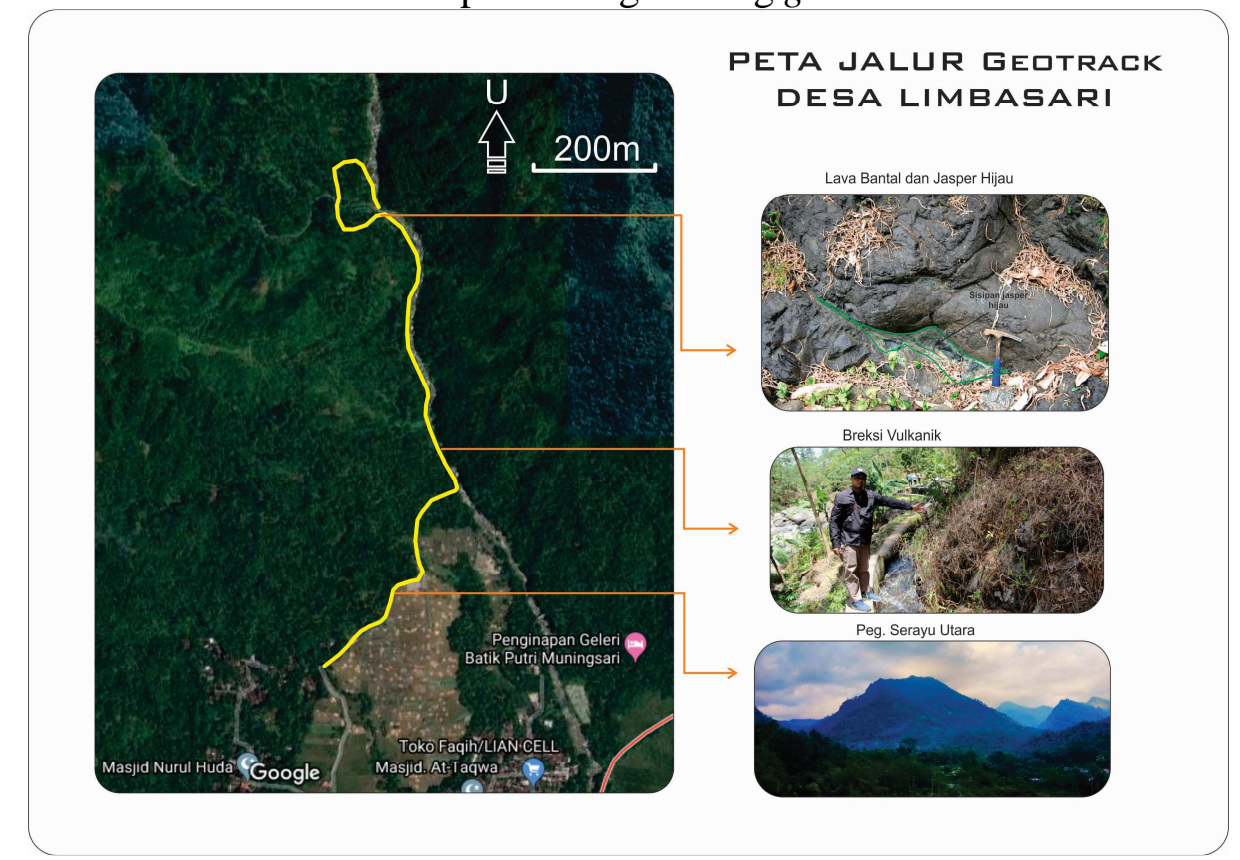

Gambar 1. Peta Geotrack Desa Limbasari dengan pemandangan berupa perbukitan dan lava bantal.

\section{a. Lava Bantal}

Lokasi Geosite ini terletak pada koordinat UTM 49S 320949, 9197177 pada jalur geotrack limbasari. Geosite ini dapat ditempuh melalui jalur darat yaitu melalui jalan ke area wisata patrawisa sejauh $20 \mathrm{~km}$ dari Purbalingga Kota. Kuantifikasi: Tabel II menunjukkan hasil analisis geosite dan geomorphosite berupa nilai pendekatan ilmiah dan intrinsik sebesar 75\%, nilai edukasi $87,5 \%$, nilai ekonomi 50\%, nilai konservasi $62,5 \%$ dan nilai tambahan $0 \%$. Secara keseluruhan, Lava Bantal memiliki tingkat kelayakan sebesar 55\% untuk dijadikan sebagai tempat geowisata. Kondisi Geologi: Lava Bantal ini berada pada daerah perbukitan serayu utara yang berada pada daerah Pegunungan Utara. Litologi dominan penyusun geosite ini adalah lava dan breksi vulkanik yang merupakan bagian dari Formasi Kumbang. Produk Daya Tarik Wisata:

1) Melihat lava bantal (batuan beku yang terbentuk di dalam air)

2) Pemandangan berupa jajaran pegunungan yang memiliki sungai yang sangat jernih sehingga dapat dijadikan sebagai obyek fotografi.

3) Wisata susur sungai menggunakan ban dalam bus dan tracking di hutan perhutani.

4) Tersedianya spot selfie. 


\section{b. Breksi vulkanik}

Lokasi Geosite ini terletak pada koordinat UTM 49S 320712, 9196827 pada jalur geotrack patrawisa. Geosite ini dapat ditempuh melalui jalur darat yaitu melalui jalan ke area wisata patrawisa sejauh $20 \mathrm{~km}$ dari Purbalingga Kota. Kuantifikasi: Tabel II menunjukkan hasil analisis geosite dan geomorphosite berupa nilai pendekatan ilmiah dan intrinsik sebesar 50\%, nilai edukasi $75 \%$, nilai ekonomi $50 \%$, nilai konservasi $50 \%$ dan nilai tambahan 0\%. Secara keseluruhan, Breksi Vulkanik memiliki tingkat kelayakan sebesar $47.5 \%$ untuk dijadikan sebagai tempat geowisata. Kondisi Geologi: Breksi Vulkanik ini berada pada daerah perbukitan serayu utara yang berada pada daerah Pegunungan Utara. Litologi dominan penyusun geosite ini adalah lava dan breksi vulkanik yang merupakan bagian dari Formasi Kumbang. Produk Daya Tarik Wisata:

1) Belajar tentang produk gunung api

2) Pemandangan berupa jajaran pegunungan yang memiliki sungai yang sangat jernih sehingga dapat dijadikan sebagai obyek fotografi.

3) Wisata susur sungai menggunakan ban dalam bus dan tracking di hutan perhutani.

4) Spot selfie

\section{c. Batu Jasper Hijau}

Lokasi Geosite ini terletak pada koordinat UTM 49S 320903, 9197320 pada jalur geotrack patrawisa. Geosite ini dapat ditempuh melalui jalur darat yaitu melalui jalan ke area wisata patrawisa sejauh $20 \mathrm{~km}$ dari Purbalingga Kota. Kuantifikasi : Tabel II menunjukkan hasil analisis geosite dan geomorphosite berupa nilai pendekatan ilmiah dan intrinsik sebesar $87.5 \%$, nilai edukasi $87,5 \%$, nilai ekonomi $75 \%$, nilai konservasi $62,5 \%$ dan nilai tambahan 55\%. Secara keseluruhan, Jasper Hijau memiliki tingkat kelayakan sebesar $73.5 \%$ untuk dijadikan sebagai tempat geowisata. Kondisi Geologi: Jasper Hijau ini berada pada daerah perbukitan serayu utara yang berada pada daerah Pegunungan Utara menyisip para celah-celah lava bantal. Litologi dominan penyusun geosite ini adalah lava yang merupakan bagian dari Formasi Kumbang. Produk Daya Tarik Wisata:

1) Pemandangan berupa tebing tinggi yang memiliki sungai yang sangat jernih sehingga dapat dijadikan sebagai obyek fotografi.

2) Wisata susur sungai menggunakan ban dalam bus dan tracking di hutan perhutani.

\section{d. Perbukitan Serayu Utara}

Lokasi Geomorphosite ini terletak pada koordinat UTM 49S 320933, 9197281 pada jalur geotrack patrawisa. Geomorphosite ini dapat ditempuh melalui jalur darat yaitu melalui jalan ke area wisata patrawisa sejauh 20km dari Purbalingga Kota. Kuantifikasi: Tabel II menunjukkan hasil analisis geomorphosite berupa nilai pendekatan ilmiah dan intrinsik sebesar $50 \%$, nilai edukasi $75 \%$, nilai ekonomi $87.5 \%$, nilai konservasi $75 \%$ dan nilai tambahan 50\%. Secara keseluruhan, Lava Bantal memiliki tingkat kelayakan sebesar 70\% 


\section{Indonesian Journal of Community Services}

Volume 2, No. 2, November 2020

http://jurnal.unissula.ac.id/index.php/ijocs

DOI: http://dx.doi.org/10.30659/ijocs.2.2.109-117

untuk dijadikan sebagai tempat geowisata. Kondisi Geologi: Geomorphosite ini berada pada daerah perbukitan serayu utara yang berada pada daerah Pegunungan Utara. Litologi dominan penyusun geomorphosite ini adalah lava dan breksi vulkanik yang merupakan bagian dari Formasi Kumbang. Produk Daya Tarik Wisata:

1) Pemandangan berupa jajaran pegunungan yang memiliki sungai yang sangat jernih sehingga dapat dijadikan sebagai obyek fotografi.

2) Wisata susur sungai menggunakan ban dalam bus dan tracking di hutan perhutani.

3) Tersedianya camping ground apabila wisatawan ingin berkemah di hutan.

4) Spot selfie.

\section{Pengembangan yang perlu dilakukan}

Beberapa penilaian terhadap geosite yang ada di kawasan Limbasari telah dilakukan. Pembenahan dari sarana prasarana terhadap setiap geosite harus dilakukan, agar terciptanya tempat wisata yang nyaman dan dapat meningkatkan perekonomian masyarakat yang tinggal di sekitar Limbasari. Berikut adalah beberapa pengembangan yang diperlukan:

- Pengembangan infrastruktur seperti jalan, papan nama, WC umum, dan kantong parkir.

- Pengembangan masyarakat tentang bagaimana mengelola wisata yang baik.

- Pengembangan promosi tentang daya tarik geowisata di Limbasari.

Tabel 1. Parameter kuantifikasi geowisata (Nuhung, 2016).

\begin{tabular}{|c|c|c|}
\hline \multicolumn{2}{|c|}{ Nilai pendekatan ilmiah dan intrinsik } & Bobot \\
\hline \multirow{3}{*}{ Integritas (A) } & Lokasi site rusak parah & 0 \\
\hline & $\begin{array}{l}\text { Lokasi site rusak, tapi masih } \\
\text { dapat terlihat } \\
\text { lingkungan abiotiknya }\end{array}$ & 0.5 \\
\hline & Site tanpa kerusakan & 1 \\
\hline \multirow{3}{*}{$\begin{array}{l}\text { Keunikan/kekhasan (jumlah } \\
\text { site yang mirip } \\
\text { dengan site tersebut) (B) }\end{array}$} & Lebih dari 5 & 0 \\
\hline & $2-5$ site yang mirip & 0.5 \\
\hline & Hanya 1 yaitu site tersebut. & 1 \\
\hline \multirow{3}{*}{$\begin{array}{c}\text { Keberagaman, jumlah proses- } \\
\text { proses geomorfik yang berbeda yang } \\
\text { dapat terlihat } \\
\text { keberagamannya }(\mathrm{C})\end{array}$} & Hanya 1 fitur/proses yang terlihat & 0 \\
\hline & 2-4 fitur/proses terlihat & 0.5 \\
\hline & Lebih dari 5 fitur/proses terlihat & 1 \\
\hline \multirow{3}{*}{$\begin{array}{c}\text { Apakah site pernah } \\
\text { dipublikasikan atau } \\
\text { diketahui secara ilmiah? (D) }\end{array}$} & Site tidak diketahui & 0 \\
\hline & $\begin{array}{l}\text { Pada paper ilmiah setingkat } \\
\text { nasional }\end{array}$ & 0.5 \\
\hline & $\begin{array}{l}\text { Diketahui secara luas oleh } \\
\text { masyarakat global }\end{array}$ & 1 \\
\hline \multicolumn{2}{|c|}{ Nilai pendidikan } & Bobot \\
\hline \multirow[b]{2}{*}{$\begin{array}{l}\text { Keterwakilan, kejelasan dari } \\
\text { proses/fitur yang ada (A) }\end{array}$} & $\begin{array}{l}\text { Keterwakilan/kejelasan rendah } \\
\text { alias tidak jelas }\end{array}$ & 0 \\
\hline & $\begin{array}{c}\text { Keterwakilan/kejelasan medium, } \\
\text { dapat dikenali } \\
\text { oleh akademisi }\end{array}$ & 0.5 \\
\hline
\end{tabular}




\section{Indonesian Journal of Community Services}

Volume 2, No. 2, November 2020

http://jurnal.unissula.ac.id/index.php/ijocs

DOI: http://dx.doi.org/10.30659/ijocs.2.2.109-117

\begin{tabular}{|c|c|c|}
\hline & $\begin{array}{l}\text { Keterwakilan/kejelasan tinggi, } \\
\text { dapat dikenali oleh } \\
\text { masyarakat luas }\end{array}$ & 1 \\
\hline \multirow{3}{*}{ Penggunaan pedagogi (B) } & $\begin{array}{l}\text { Nilai karakter yang rendah dan } \\
\text { tanpa penggunaan } \\
\text { unsur/proses pendidikan }\end{array}$ & 0 \\
\hline & $\begin{array}{l}\text { Ada nilai karakter tetapi } \\
\text { penggunaan unsur } \\
\text { pendidikan yang terbatas }\end{array}$ & 0.5 \\
\hline & $\begin{array}{c}\text { Nilai karakter yang tinggi dan } \\
\text { potensi unsur } \\
\text { pendidikan yang tinggi, aspek geowisata } \\
\text { yang } \\
\text { tinggi }\end{array}$ & 1 \\
\hline \multirow{3}{*}{$\begin{array}{l}\text { Apakah telah ada produk } \\
\text { pendidikan di sitetersebut }(\mathrm{C})\end{array}$} & Tidak ada petunjuk informasi & 0 \\
\hline & Ada leaflets, peta, laman internet & 0.5 \\
\hline & $\begin{array}{l}\text { Ada panel informasi di lokasi site } \\
\text { tersebut }\end{array}$ & 1 \\
\hline \multirow{3}{*}{$\begin{array}{l}\text { Penggunaan nyata atau aktual } \\
\text { dari site tersebut untuk kepentingan } \\
\text { pendidikan (D) }\end{array}$} & $\begin{array}{l}\text { Tidak ada penggunaan untuk } \\
\text { pendidikan }\end{array}$ & 0 \\
\hline & $\begin{array}{l}\text { Digunakan untuk ekskursi atau } \\
\text { fieldtrip khusus } \\
\text { bagi siswa } \\
\end{array}$ & 0.5 \\
\hline & $\begin{array}{l}\text { Tempat umum untuk dikunjungi } \\
\text { public }\end{array}$ & 1 \\
\hline \multicolumn{2}{|c|}{ Nilai Ekonomi } & Bobot \\
\hline \multirow{3}{*}{ Daya akses, (A) } & Lebih dari $1 \mathrm{~km}$ dari lokasi parkir & 0 \\
\hline & $\begin{array}{l}\text { Kurang dari } 1 \mathrm{~km} \text { dari lokasi } \\
\text { parkir }\end{array}$ & 0.5 \\
\hline & $\begin{array}{l}\text { Lebih dari } 1 \mathrm{~km} \text { dari } \\
\text { pemberhentian transportasi } \\
\text { publik }\end{array}$ & 1 \\
\hline \multirow{3}{*}{$\begin{array}{l}\text { Kehadiran infrastruktur } \\
\text { penunjang } \\
\text { pariwisata, }(\mathrm{B})\end{array}$} & $\begin{array}{l}\text { Lebih dari } 10 \mathrm{~km} \text { dari lokasi } \\
\text { fasilitas pariwisata yang telah ada }\end{array}$ & 0 \\
\hline & $\begin{array}{l}\text { 5-10 km dari fasilitas pariwisata } \\
\text { yang telah ada }\end{array}$ & 0.5 \\
\hline & $\begin{array}{l}\text { Kurang dari } 5 \mathrm{~km} \text { dari fasilitas } \\
\text { pariwisata yang } \\
\text { telah ada }\end{array}$ & 1 \\
\hline \multirow{3}{*}{ Produk lokal terkait (C) } & $\begin{array}{l}\text { Tidak ada produk lokal yang } \\
\text { terkait dengan situs wisata }\end{array}$ & 0 \\
\hline & Beberapa produk terkait & 0.5 \\
\hline & Pusat beberapa produk tertentu & 1 \\
\hline \multicolumn{2}{|c|}{ Nilai Konservasi } & Bobot \\
\hline \multirow{3}{*}{$\begin{array}{l}\text { Resiko nyata atau sudah jelas- } \\
\text { jelas ada seperti misalnya banjir rob } \\
\text { untuk site di pesisir, (A) }\end{array}$} & $\begin{array}{l}\text { Resiko tinggi, tinggi resiko alami } \\
\text { dan buatan }\end{array}$ & 0 \\
\hline & $\begin{array}{l}\text { Ada resiko yang dapat } \\
\text { mengganggu }\end{array}$ & 0.5 \\
\hline & $\begin{array}{l}\text { Resiko sangat rendah bahkan } \\
\text { tanpa ada ancaman }\end{array}$ & 1 \\
\hline $\begin{array}{c}\text { Resiko yang masih } \\
\text { berpotensial, belum terjadi, (B) }\end{array}$ & $\begin{array}{l}\text { Resiko tinggi, tinggi resiko alami } \\
\text { dan buatan }\end{array}$ & 0 \\
\hline
\end{tabular}

\section{4 || Indonesian Journal of Community Services}




\begin{tabular}{|c|c|c|}
\hline & $\begin{array}{l}\text { Ada resiko yang dapat } \\
\text { mengganggu }\end{array}$ & 0.5 \\
\hline & $\begin{array}{l}\text { Resiko sangat rendah bahkan } \\
\text { tanpa ada ancaman }\end{array}$ & 1 \\
\hline \multirow{3}{*}{$\begin{array}{l}\text { Status terbaru dari site } \\
\text { tersebut }(\mathrm{C})\end{array}$} & Proses perusakan terus terjadi & 0 \\
\hline & $\begin{array}{l}\text { Site rusak, tapi ada managemen } \\
\text { untuk } \\
\text { mencegahnya }\end{array}$ & 0.5 \\
\hline & Tidak ada proses perusakan & 1 \\
\hline \multirow{3}{*}{$\begin{array}{l}\text { Perlindungan undang- } \\
\text { ndang/perda tentang site tersebut (D) }\end{array}$} & $\begin{array}{l}\text { Tidak ada hukum yang } \\
\text { melindungi }\end{array}$ & 0 \\
\hline & Baru bersifat pengajuan & 0.5 \\
\hline & $\begin{array}{l}\text { Sudah ada perda/hukum untuk } \\
\text { mengkonservasinya }\end{array}$ & 1 \\
\hline \multicolumn{2}{|c|}{ Nilai Tambahan } & Bobot \\
\hline \multirow{3}{*}{$\begin{array}{l}\text { Nilai budaya, agama, sejarah } \\
\text { yang terkait dengan site tersebut (A) }\end{array}$} & Tidak ada unsur budaya & 0.5 \\
\hline & $\begin{array}{l}\text { Ada unsur budaya namun tidak } \\
\text { terlalu berkaitan } \\
\text { dengan unsur abiotik }\end{array}$ & 1 \\
\hline & $\begin{array}{l}\text { Ada hubungan budaya yang kuat } \\
\text { dengan unsur } \\
\text { abiotik, misalnya mistis }\end{array}$ & 0 \\
\hline \multirow[t]{3}{*}{ Nilai ekologi (B) } & $\begin{array}{l}\text { Tidak penting karena kurangnya } \\
\text { makhluk hidup }\end{array}$ & 0 \\
\hline & $\begin{array}{l}\text { Ada pengaruh tapi tidak terlalu } \\
\text { penting }\end{array}$ & 0.5 \\
\hline & $\begin{array}{l}\text { Pentingnya pengaruh dari aspek } \\
\text { geomorfik } \\
\text { terhadap ekologi di sekitarnya }\end{array}$ & 1 \\
\hline \multirow[t]{9}{*}{$\begin{array}{c}\text { Nilai Estetika (C): Jumlah } \\
\text { Warna (D); Struktur Ruang dan } \\
\text { Pemandangan (E) }\end{array}$} & 1 warna & 0 \\
\hline & 2-3 warna & 0.25 \\
\hline & Lebih dari 3 warna & 0.5 \\
\hline & Hanya 1 pola & 0 \\
\hline & $\begin{array}{l}2 \text { atau } 3 \text { Pola yang dapat } \\
\text { dibedakan }\end{array}$ & 0 \\
\hline & Lebih dari 3 pola & 0.5 \\
\hline & Tidak ada & 0 \\
\hline & $1-2$ & 0.25 \\
\hline & 3 dan lebih & 0.5 \\
\hline
\end{tabular}

Tabel 2. Tabel Hasil Kuantifikasi Kelayakan

\begin{tabular}{ccccc}
\hline Parameter & Lava Bantal & $\begin{array}{c}\text { Breksi } \\
\text { Vulkanik }\end{array}$ & $\begin{array}{c}\text { Jasper } \\
\text { Hijau }\end{array}$ & $\begin{array}{c}\text { Peg. Serayu } \\
\text { Utara }\end{array}$ \\
\hline \multicolumn{7}{c}{ Nilai Pendekatan Ilmiah dan Intrinsik } & 1 \\
\hline A & 1 & 1 & 1 & 0 \\
\hline B & 0.5 & 0 & 0.5 & 1 \\
\hline C & 1 & 0.5 & 1 & 1 \\
\hline D & 0.5 & 0.5 & 1 & \\
\hline$(\%)$ & 75 & 50 & 87.5 & 1 \\
\hline A & 1 & NIlai Pendidikan & & 1 \\
\hline B & 1 & 0.5 & 1 & 1 \\
\hline
\end{tabular}




\begin{tabular}{ccccc}
\hline $\mathrm{C}$ & 0.5 & 0.5 & 0.5 & 0.5 \\
\hline $\mathrm{D}$ & 1 & 1 & 1 & 1 \\
\hline$(\%)$ & 87.5 & 75 & 87.5 & 87.5 \\
\hline $\mathrm{A}$ & 1 & Nilai Ekonomi & & 1 \\
\hline $\mathrm{B}$ & 1 & 1 & 1 & 1 \\
\hline $\mathrm{C}$ & 0 & 1 & 1 & 0 \\
\hline$(\%)$ & 50 & 0 & 1 & 50 \\
\hline & & 50 & 75 & 1 \\
\hline $\mathrm{A}$ & 1 & Nilai Konservasi & & 1 \\
\hline $\mathrm{B}$ & 0.5 & 1 & 1 & 1 \\
\hline $\mathrm{C}$ & 1 & 0.5 & 0.5 & 0 \\
\hline $\mathrm{D}$ & 0 & 1 & 1 & 75 \\
\hline$(\%)$ & 62.5 & 0 & 0 & 0 \\
\hline & & 62.5 & 62.5 & 1 \\
\hline $\mathrm{A}$ & 0 & Nilai Tambahan & & 1 \\
\hline $\mathrm{B}$ & 0 & 0 & 1 & 0.5 \\
\hline $\mathrm{C}$ & 0 & 0 & 0 & 62.5 \\
\hline $\mathrm{D}$ & 0 & 0 & 1 & $\mathbf{7 0}$ \\
\hline (\%) & 0 & 0 & 0.25 & 55 \\
\hline Total (\%) & $\mathbf{5 5}$ & 0 & $\mathbf{7 3 . 5}$ & \\
\hline & & $\mathbf{4 7 . 5}$ & & \\
\hline
\end{tabular}

\section{KESIMPULAN}

Dari hasil pengabdian ini kawasan Geowisata Limbasari, Kabupaten Purbalingga dijumpai banyak obyek potensial untuk dijadikan wisata berbasis geologi. Pada lokasi ini ditemukan 4 geosite, yaitu Lava Bantal, Breksi Vulkanik, Jasper Hijau, dan Morfosite Pegunungan Serayu Utara yang mempunyai nilai kelayakan secara berurutan 55\%, 47.5\%, 73.5\%, dan 70\%. Jasper Hijau dan Pegunungan Serayu Utara merupakan geosite dan morphosite yang sangat layak dijadikan tempat wisata karena tersedianya fasilitas penunjang wisata yang lengkap. Sementara geosite yang lain masih harus dilakukan pembenahan dari segi infrastruktur penunjang wisata maupun pembentukan masyarakat yang sadar wisata.

\section{UCAPAN TERIMA KASIH}

Kami sampaikan terimakasih kepada rekan-rekan dosen Fakultas Teknik Universitas Jenderal Soedirman, masyarakat Desa Limbasari dan jajaran pemerintah desa yang turut ikut membantu dalam pengabdian ini. Semoga tulisan ini berguna kedepannya.

\section{DAFTAR PUSTAKA}

Ernawati, N. M., Basi Arjana, I. W., \& Jendra, W. (2019). Jasa penginapan pendukung geowisata di Batur Bali. Jurnal Bisnis Dan Kewirausahaan. https://doi.org/10.31940/jbk.v15i1.1078

Hidayat, H. N., Fauzi, Z., \& Heliani, L. S. (2017). Analisis geosite dan geomorphosite kawasan karsbiduk-biduk sebagai potensi geowisata Indonesia. Proceeding, Seminar Nasional Kebumian Ke-10.

Inskeep E. (2010). Tourism planning: An integrated and sustainable development approach. Oxford: OUP 
Kirchner, K., \& Kubalíková, L. (2014). Geosite and geomorphosite assessment for geotourism purpose: A case study from the Vizovická Vrchovina Highland, Eastern Moravia. Public Recreation and Landscape Protection-with Man Hand in Hand? 2014 Conference Proceeding.

Laksono, F. A. T., Santoso, P. B., \& Permanajati, I. (2020). Peningkatan nilai tambah Curug Bandung, Desa Sumingkir, Kecamatan Kutasari, Kabupaten Purbalingga sebagai destinasi geowisata baru. Dinamika Journal: Pengabdian Masyarakat. https://doi.org/10.20884/1.dj.2020.2.1.933

Murdana, I. B. P. (2015). Pengembangan Desa Wisata Rural-Geotourism berbasis kearifan lokal dengan metode SLA untuk pemberdayaan masyarakat miskin di kawasan Gunung BaturKintamani Kabupaten Bangli. In eproceeding UNDIKSHA.

Nuhung, S. (2016). Karst Maros Pangkep menuju Geopark Dunia (tinjauan dari aspek geologi lingkungan). Jurnal Plano Madani.

Pakpahan, R. (2018). Implementasi prinsip pariwisata berbasis komunitas di Desa Wisata Nglinggo Yogyakarta. Jurnal Master Pariwisata (JUMPA). https://doi.org/10.24843/jumpa.2018.v05.i01.p07

Permadi, R., Rachmat, H., \& Manullang, S. (2016). Peran geopark nasional rinjani dalam mendukung pengembangan ekowisata, geokonservasi dan geowisata. Fakultas Teknik Geologi, Universitas Padjadjaran.

Prihasta, A. K., \& Suswanta, S. (2020). Pengembangan Desa Wisata Berbasis Pemberdayaan Masyarakat Desa Wisata Kaki Langit Padukuhan Mangunan. Jurnal Master Pariwisata (JUMPA). https://doi.org/10.24843/jumpa.2020.v07.i01.p10

Riswanto, A., \& Andriani, R. (2018). Maksimalisasi potensi geowisata dalam meningkatkan kunjungan wisatawan. Jurnal Pariwisata. https://doi.org/10.31311/par.v5i2.4428

Sidik, F. (2015). Menggali potensi lokal mewujudkan kemandirian desa. JKAP (Jurnal Kebijakan dan Administrasi Publik). https://doi.org/10.22146/jkap.7962

Wijaya, I. P. K., \& Widodo, A. (2015). Potensi geowisata Bukit Jamur Kecamatan Bungah, Kabupaten Gresik, Provinsi Jawa Timur. Jurnal Geosaintek. https://doi.org/10.12962/j25023659.v1i1.1199

Zaenudin, A., Suharno, Haerudin, N., \& Darmawan, I. G. B. (2019). Pemetaan potensi geowisata dan upaya peningkatan partisipasi masyarakat dalam tata kelola pariwisata di Air Naningan, Tanggamus. SENAPATI. 